\title{
Desvendando a ecologia local: Atividades interativas
}

\author{
Janilda Pacheco da Costa \\ Antonio Carlos Concellos Costa \\ Sonia Peres
}

Gerlinde Agate P. Brasil Teixeira

\begin{abstract}
Resumo
Embora nem sempre percebido, a Educação Ambiental é um tema que perpassa tanto por diversas áreas do conhecimento como pelo cotidiano das pessoas. Assim se presta facilmente para a realização de atividades interdisciplinares. Relatamos uma ação educativa desenvolvida em uma escola pública de Maricá, RJ, onde foi observado que a comunidade não valorizava o ambiente natural no seu entorno apesar da região possuir diversas áreas de preservação ambiental. Foram propostas e realizadas várias estratégias educacionais que envolveram o conhecimento das áreas naturais existentes na região, a saber: Restinga, Mata Atlântica, complexo lagunar e sistema costeiro. Durante a ação os estudantes demonstraram uma mudança no olhar não só para as questões ambientais (antes discutidas de forma distante em sala de aula), mas também para a conservação do ambiente local. Desta forma, confirmamos que ações interdisciplinares associadas à utilização de estratégias educacionais variadas levam a bons resultados no processo ensino-aprendizagem.
\end{abstract}

Palavras-chave: Educação ambiental, estratégias educacionais,
interdisciplinaridade.

\section{Abstract}

\section{Unraveling the local ecology: interactive activities}

Although not always perceived environmental education is a theme that permeates many areas of knowledge but is also present in daily life, lending itself easily to the employment of interdisciplinary activities that. We report an educational activity developed in a public school of Maricá-RJ, whose community did not value the natural environment in their surroundings despite of the presence of preservation areas in the region. A diversity of strategies involving the knowledge of several natural areas as restinga, Atlantic forest, coastal and lagoonary systems were proposed and developed. During the action the students 
demonstrated a change in the look not only for environmental issues (previously discussed superficially in the classroom), but also to conservation of the local environment. Thus, the interdisciplinary approach associated with the use of diverse educational strategies often lead to good results in the teaching-learning process.

Keywords: education, technology, environmental education

\section{Introdução}

A crescente discussão sobre as conseqüências das ações humanas sobre o planeta na segunda metade do século XX levou à organização, no ano de 1977, em Tibilisi, da Conferência Mundial sobre o Meio Ambiente Humano. Neste encontro, foi levantada a necessidade de ser gerado um amplo processo de educação ambiental (EA) como forma de conscientização e discussão a respeito dos problemas ambientais locais e mundiais. A Constituição Brasileira de 1988 possui um capítulo dedicado à questão ambiental, onde se afirma caber ao Poder Público "promover a EA em todos os níveis de ensino e a conscientização pública para a preservação do meio ambiente."(Brasil, 1988).

O século XXI trouxe consigo uma série de questionamentos e revisões sobre os olhares utilizados para apreender e compreender a realidade que nos cerca. Os princípios - ordem, separabilidade e lógica - do paradigma cartesiano positivista, que caracteriza o "olhar clássico" da ciência, já não conseguem dar conta dos problemas que se apresentam para a ciência e para os cientistas. O pensamento reducionista e simplificador já não é suficiente para conhecermos o mundo que nos rodeia e ao qual pertencemos.

Segundo Edgar Morim, precisamos avançar e "ligar o concreto das partes à totalidade" de tal modo que seja possível articularmos "os princípios da ordem e da desordem, da separação e da junção, da autonomia e da dependência, que estão em dialógica (complementares, concorrentes e antagônicos) no seio do universo"(Morin e Le Moigne, 2000)

Atendendo a esta necessidade contemporânea os Parâmetros Curriculares Nacionais (PCN) do Ministério da Educação colocam que a EA deve ser trabalhada na educação formal como um tema transversal desde as primeiras séries do Ensino fundamental. Sendo assim, o trabalho interdisciplinar é o ponto chave para a ação em EA para que todos os aspectos relacionados a esta questão possam ser abordados(Brasil, 2002)

O olhar interdisciplinar sobre a realidade permite que a relação entre o todo e as partes que a constituem seja mais bem entendido (Goldman, 1979), rompendo as fronteiras disciplinares e assim, garantindo a construção de um conhecimento globalizante (Gadotti, 2004). Thiesen, discutindo interdisciplinaridade, afirma que no campo conceitual ela será sempre uma reação 
alternativa à abordagem disciplinar normalizadora (seja no ensino ou pesquisa) dos diversos objetos de estudo (Thiesen, 2008).

Refletir sobre a complexidade ambiental abre uma estimulante oportunidade para compreender a gestação de novos atores sociais que se mobilizam para a apropriação da natureza, para um processo educativo articulado e compromissado com a sustentabilidade e a participação, apoiado numa lógica que privilegia o diálogo e a interdependência de diferentes áreas do saber.(Jacobi, 2003)

A interdisciplinaridade resulta de uma construção consciente do conhecimento e dos saberes. (Leff, 2000). Ou seja, a abordagem temática remete à interdisciplinaridade, considerando que a complexidade dos temas requer a análise sob vários olhares articulados em torno de um tema aberto, sendo os problemas ambientais representantes típicos. Supera-se, assim, uma compreensão de interdisciplinaridade, bastante problemática, que se limita a buscar interfaces entre as disciplinas constituintes dos currículos tradicionais das escolas.(Auler, 2007)

Independente da definição que cada autor assuma, a interdisciplinaridade está sempre situada no campo onde se exprime a resistência sobre um saber parcelado enquanto se pensa a possibilidade de superar a fragmentação das ciências e dos conhecimentos produzidos por elas (Thiesen, 2008).

A promoção de uma educação científica que permita ao educando adquirir competências para interpretar a complexidade do mundo atual, pode ocorrer sem a alteração da estrutura disciplinar. No entanto, neste processo de ensino e aprendizagem devem ser inseridos "momentos interdisciplinares" em tempos específicos do trabalho pedagógico como uma forma de relacionar, articular e integrar os conhecimentos (Batista e Salvi, 2006). Desse modo, na escola, a Educação Ambiental (que possibilita momentos interdisciplinares) aproxima o sujeito de sua realidade mais ampla, possibilitando uma formação mais consistente e responsável dando maior significado e sentido aos conteúdos da aprendizagem (Thiesen, 2008).

Assim, quanto mais relações conceituais entre as diferentes ciências forem estabelecidas, quanto mais problematizadores, estimuladores, desafiadores e dialéticos forem os métodos de ensino, maior será a possibilidade de apreensão do mundo pelos sujeitos que aprendem (Hartmann e Zimmermann, 2007).

Diversos autores também discutem a importância de novas técnicas e materiais como ferramentas para a melhoria do processo de ensino e aprendizagem. A utilização de tecnologias em educação permite estimular o aluno na medida em que ele "vê" a situação além do uso das palavras, permitindo assim um processo criativo mais intenso, dinâmico e prazeroso, onde o aluno também é produtor e criador de mensagens, construindo gradualmente sua visão de mundo a partir de distintos universos. (Lewis, 2005; Rodrigues e Colesanti, 2008). Este mesmo processo é discutido por Mishra e Koehler no uso de suportes tecnológicos pedagógicos (TPCK), 
onde o conhecimento do conteúdo e a ação pedagógica são permeados por ferramentas tecnológicas de modo a facilitar o aprendizado. O recurso tecnológico per si não levará a mudanças conceituais. De acordo com o conteúdo a ser trabalhado e o objetivos que se deseja alcançar, caberá ao professor avaliar como, quando e qual tecnologia utilizar. Assim a capacitação tecnológica dos profissionais da educação é de extrema importância (Mishra e Koehler, 2006). 0 impacto no uso de novas tecnologias educacionais só terá efetivo resultado se forem utilizadas não somente como base de dados, mas também como simuladores de casos, vídeos e imagens, discutindo-se sempre a validade do material a partir de critérios bem precisos determinados pelo professor (Jones e Moreland, 2004; Rodrigues e Colesanti, 2008).

O ensino convencional de ciências não vem formando adequadamente os indivíduos para sua atuação na sociedade. Segundo Santos e Mortimer o agravamento dos problemas ambientais pós-guerra, a necessidade de participação popular nas decisões públicas e, sobretudo, o medo e as frustrações decorrentes dos excessos tecnológicos são algumas das causas que propiciaram o surgimento das propostas para o ensino com enfoque em Ciência, Tecnologia e Sociedade (CTS). $\mathrm{Na}$ educação com enfoque CTS são discutidos muitos outros aspectos além da natureza da investigação e do significado dos conceitos científicos.(Santos e Mortimer, 2002)

Com esta visão de ciência, o enfoque CTS nos currículos no ensino médio permite que o aluno inicie um questionamento de sua ação na sociedade, estimulando a curiosidade e o espírito investigador. Emerge daí a necessidade de buscar elementos para a resolução de problemas que fazem parte do cotidiano do aluno, ampliando-se esse conhecimento para utilizá-lo nas soluções dos problemas coletivos de sua comunidade e sociedade.(Pinheiro et al., 2007)

Neste sentido, a educação ambiental tem se tornado cada vez mais importante, como um meio de buscar apoio e participação dos diversos segmentos da sociedade para a conservação e a melhoria da qualidade de vida, uma vez que propicia ampliação dos conhecimentos, a mudança de valores e o aperfeiçoamento de habilidades, que juntos podem fazer com que os homens assumam comportamentos e atitudes que estejam em harmonia com o meio ambiente (Padua e Tabanez 1997 ).

Relacionando interdisciplinaridade, educação ambiental e uso de ferramentas tecnológicas buscamos neste artigo relatar uma ação educativa que teve como proposta a utilização de ferramentas tecnológicas em EA desenvolvida de forma interdisciplinar e participativa. 


\section{Materiais e métodos \\ Descrição da área de estudo}

O município de Maricá está localizado na Região Metropolitana do Estado do Rio de Janeiro, cujos limites são: ao norte com os municípios de Itaboraí e de Rio Bonito; ao sul com o Oceano Atlântico; a leste com o município de Saquarema; e a oeste com os municípios de São Gonçalo e Niterói. Sua área é de 363,3 km².

Tem clima tropical com variações de acordo com a proximidade do mar e altitude. Em função da variedade de altitudes a região possui diversos ecossistemas da Mata Atlântica, como florestas do tipo tropical de altitude, restinga e planícies costeiras. Segundo o Decreto Lei 750/93, - Domínio da Mata Atlântica(DMA), é definido como:"O espaço que contém aspectos fitogeográficos e botânicos que tenham influência das condições climatológicas peculiares do mar (Joly/70) incluindo as áreas associadas delimitadas segundo o Mapa de Vegetação do Brasil (IBGE,1993) que inclui as Florestas Ombrófila Densa, Floresta Ombrófila Mista, Floresta Ombrófila Aberta, Floresta Estacional Semidecidual e Floresta Estacional Decidual, manguezais, restingas e campos de altitude associados, brejos interioranos e encraves florestais da Região Nordeste". (IBGE, 1992)

O município de Maricá possui também uma bacia hidrográfica com pequenos rios e um sistema lagunar que acompanha os $30 \mathrm{~km}$ de litoral. Em sua bacia hidrográfica destacam-se as lagunas de Maricá, Barra, Guarapina, Jaconé e Brava, os rios Mombuca e Ubatiba, e os canais da Costa e Ponta Negra (Jardim et al., 2004).

As praias de Maricá são de tombo, em mar aberto, com areias grossas, boas apenas para a pesca. A Praia de Itaipuaçu é uma das maiores do Estado $(36 \mathrm{~km})$ e muito perigosa com ondas fortes, valas e correnteza. Os melhores pontos para banho são o Recanto e a ponta da divisa com o município de Niterói. As ilhas de Maricá localizam-se a $5 \mathrm{~km}$ da costa, no distrito de Itaipuaçu dividida em 3 elementos: a Grande, as Criolas e o Anexo. A grande serve como abrigo para os pescadores e como área de pesquisa. Possui água doce e um farol de sinalização da marinha. 0 anexo é um bom pesqueiro, com fácil captura de garoupas, sargo, anchova, moluscos como a lula, o polvo e mariscos. (Pereira et al., 2001)

A restinga de Barra de Maricá apresenta dois cordões arenosos separados por uma depressão, onde ocorre um brejo de água doce originado pelo afloramento do lençol freático (Pereira et al., 2001). A Área de Proteção Ambiental (APA) da restinga de Maricá foi criada através do Decreto Estadual $\mathrm{n}^{\circ} 7.230$ de 23 de abril de 1984, com uma área total de $8,3 \mathrm{~km}^{2}$. Segundo estudos da vegetação brasileira, a palavra restinga é empregada em três sentidos: para designar todas as formações vegetais que cobrem as areias desde o oceano podendo alcançar as primeiras elevações da Serra do Mar, para designar a paisagem formada pelo areal com sua vegetação global, ou então, para indicar a vegetação lenhosa e densa da parte plana. A restinga é uma 
vegetação com influência marinha e fluvio-marinha, nas vizinhanças do oceano, aparece nas encostas baixas ou morros baixos da Serra do Mar. Depois das dunas móveis ocorrem áreas amplas nas quais as dunas estão fixadas pela vegetação. A vegetação arbóreo-arbustiva ocupa grandes extensões do litoral, sobre as dunas e planícies costeiras. Sobre o solo raso há densa formação de arbustos e árvores pequenas (5-7 metros), podendo algumas vezes atingir porte florestal quando estiver sobre solos mais profundos. Inicia-se junto à praia, com vegetação herbácea e torna-se mais desenvolvida à medida que avança para o interior. A vegetação arenícola marítima pode ser chamada de jundú.(CN-RBMA, 2004)A restinga de Maricá apresenta grande diversidade do ponto de vista botânico, sendo ideal para o refúgio de várias espécies da fauna ameaçadas de extinção, e como tal, passou a ser considerada alvo de proteção ambiental (Pereira et al., 2001). Apesar disto, tem sido continuamente destruída por ações de desmatamentos, queimadas e retirada ilegal de areia.

O Sistema Lagunar de Maricá-Guarapina é formado por uma série de lagoas costeiras interligadas por canais. Apresenta importância sócio-econômico-ambiental local e regional. Observa-se uma pressão antrópica crescente, com falta de planejamento na implantação de redes de serviços públicos, principalmente as relacionadas à distribuição de água, saneamento, malha viária e geração de energia elétrica, vem fazendo com que a área apresente sérias deficiências infra-estruturais (Cruz et al., 1996).

A preservação da flora e fauna silvestres, também encontra-se bastante comprometida, sendo comprovada a redução da produtividade de recursos naturais (principalmente a pesca), devido à destinação dos esgotos refletirem diretamente na salubridade dos cursos fluviais e na sobrevivência das lagoas.

A economia do município se sustenta na pecuária, pesca, construção civil, transportes e turismo. A história oficial do município se inicia em oito de Janeiro de 1574 , com a doação feita pelo governo do Rio de Janeiro a Antônio Marins, de uma sesmaria medindo 500 braças em quadra, na praia fronteira às ilhas Maricás, na altura da atual praia de Itaipuaçú (Brum, 2004). Ao final do século XVI padres beneditinos chegam ao Brasil e recebem uma faixa de terra junto à Barra da lagoa de Maricá, destinada a construção de uma igreja, o que ocorre em 1635. Inicia-se assim o povoamento da região. Porém, devido a um surto de malária a sede do município é transferida para o outro lado da lagoa, iniciando a Vila de Maricá. Anos mais tarde visitantes ilustres visitam o município como Charles Darwin, no ano de 1832 e a princesa Isabel e Conde D’Eu em 1868 (Cruz et al., 1996; Brum, 2004). Diversas fazendas desta época atualmente são abertas à visitação pública. 


\section{A ação: Projeto "Conhecer para conservar"}

O Colégio Estadual Dr. João Gomes de Mattos Sobrinho situa-se no bairro de Inoã, no terceiro distrito de Maricá, possuindo turmas do 6으 ano ao 9o ano do ensino fundamental e Ensino Médio. O corpo discente é composto por alunos oriundos dos bairros do entorno assim como de municípios vizinhos. A escola é Peri - urbana com forte ligação com a região costeira do município. É conhecida na região pelos seus trabalhos culturais voltados ao teatro, música e esportes.

O projeto intitulado "Conhecer para conservar" começou a ser delineado com a turma de terceiro ano do ensino médio, quando se discutiam temas gerais de Ecologia, durante as aulas de Biologia. Percebemos durante as discussões em sala que os alunos dominavam conceitos teóricos referentes à disciplina, porém não associavam estas informações aos ambientes naturais chegando ao ponto de alguns depreciarem os ambientes locais comentando de forma pejorativa sobre estes. Numa tentativa de reverter este processo iniciamos uma discussão junto com os alunos e professores de Biologia, História e Geografia sobre os conhecimentos que o grupo tinha sobre a região. Estabeleceram-se então etapas para as ações propostas na discussão tendo como título Projeto "Conhecer para conservar".

A primeira etapa, com duração de um bimestre, foi de levantamento de publicações sobre o município com o objetivo de gerar material de pesquisa para atividades posteriores. Foram utilizados diversos recursos como pesquisas na internet, livros de autores locais, livros didáticos, revistas e entrevistas com moradores.

A segunda etapa (mais um bimestre) teve início com discussões em sala de aula com a presença dos professores sobre os temas pesquisados. Nestas discussões os alunos propuseram a realização de saídas de campo de modo a registrar alguns dos dados que eles viram levantados na pesquisa bibliográfica. Com a literatura referente à paisagem natural do município e sua história em mãos, a classe foi dividida em grupos com uma média de 10 alunos. Cada grupo tinha como tarefa fotografar ou filmar um ambiente da região e desenvolver um texto a respeito. Para estas atividades de campo membros da comunidade local (membros da colônia de pescadores local e de um grupo de montanhismo) foram convidados a participar.

Durante a segunda etapa foi utilizado o laboratório de Informática da escola, e com o auxílio do técnico responsável e professores envolvidos, os alunos montaram os produtos (vídeos e edição de imagens e sons) das pesquisas de sala de aula e saída de campo, assim como um material de pesquisa com textos, o qual chamamos de cartilha.

Durante a organização das atividades anteriores foram discutidas nas aulas de Biologia, História e Geografia, as impressões dos alunos sobre os ambientes visitados, sendo proposta por eles uma exposição aberta à comunidade como forma de divulgação da importância do patrimônio histórico e ecológico local. A exposição, com a montagem de stands com maquetes, 
painéis de fotos e sessões de vídeos, abertos a visitação aos demais alunos da escola, foi então a culminância do projeto. Toda a produção textual e de imagens dos alunos foi organizada na forma de uma cartilha, sendo reproduzido em papel e na forma digital para distribuição durante a exposição.

\section{Resultados e discussão: \\ Mata Atlântica - floresta}

O grupo de Mata Atlântica fez diversos contatos com organizações não governamentais e grupos de montanhismo locais, participando com eles de caminhadas ao Parque Estadual da Serra da Tiririca (Figura 1) e Pedra de Inoã, um morro de gnaisse que é símbolo da região. O contato dos alunos com estes grupos fizeram com que eles observassem de forma diferente o ambiente. Alguns alunos relataram surpresa e alegria ao conhecerem novas informações sobre o local onde viviam tais como:

"nunca prestei atenção à beleza da região"

"não havia pensado que estes pequenos riachos fossem tão importantes para a minha vida"

"na escola falam de Amazônia e a gente com essa floresta linda aqui perto de nós"

Durante a exposição o grupo montou uma "mini floresta" com galhos de árvores, cipós e bichos de pelúcia que retratavam a fauna local como micos, pássaros e répteis. Enquanto eles descreviam o ecossistema para os visitantes, um CD de pássaros fazia uma trilha sonora. Junto com a professora de Geografia o grupo construiu uma maquete de parte do parque Estadual da Serra da Tiririca para chamar a atenção dos visitantes para a conservação da área. 


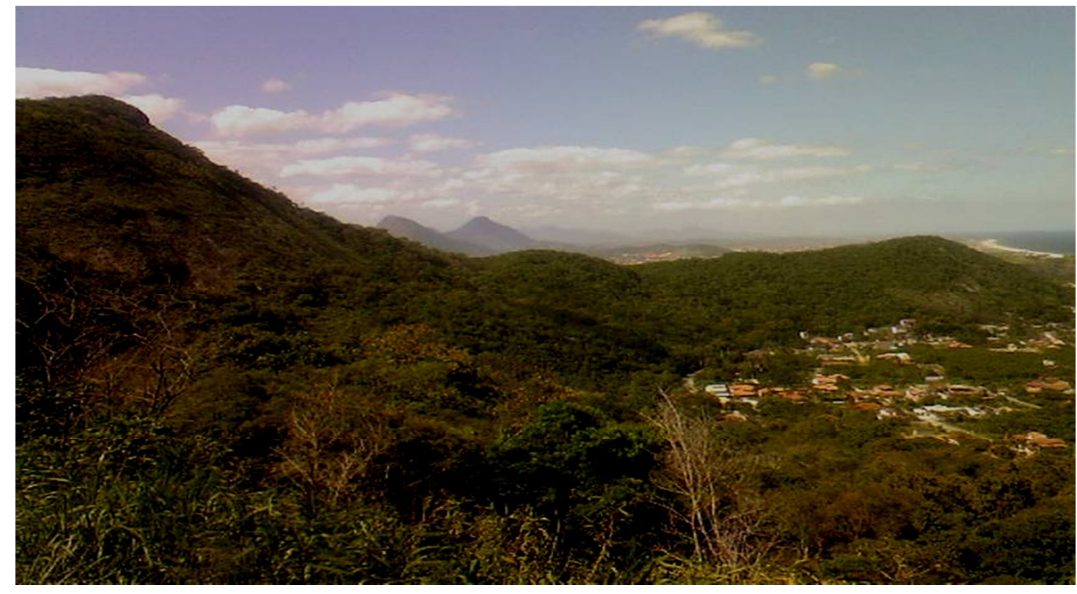

Figura 1 - Fotografia da Mata Atlântica no Parque Estadual da Serra da Tiririca-RJ -

\section{Ambiente Costeiro}

O grupo de ambiente Costeiro (Figura 2) buscou a colônia de pescadores locais. Este contato foi feito com a participação do pai de um dos alunos, que é membro da colônia. Eles conversaram com os pescadores sobre a sazonalidade dos pescados, a arte da confecção de redes e ainda, com autorização dos pais, acompanharam os pescadores em uma visita às Ilhas Maricás, a $5 \mathrm{~km}$ da costa, onde fotografaram e conheceram a fauna (ouriços, estrelas e caranguejos) e flora das ilhas (algas, pitangueiras e algumas plantas levadas do continente).

Durante a exposição o grupo montou um stand com uma tarrafa aberta enfeitada de conchas e exoesqueletos de animais, associada a fotos das praias e da saída de campo. Este grupo fez um pequeno vídeo sobre o ambiente costeiro e junto a membros de outros grupos montaram um segundo vídeo sobre todos os ambientes estudados. Esta atividade teve um grande significado para estes estudantes uma vez que foi utilizado durante a cerimônia de formatura do Ensino Médio.

Neste grupo, os alunos se mostraram mais conscientes sobre a pesca artesanal e sua importância para a manutenção do potencial pesqueiro da região:

"Nunca havia perguntado ao meu pai sobre o seu trabalho e não imaginava que ele soubesse tanto sobre os animais (peixes, moluscos e crustáceos)!"

"Ouvir dos pescadores o que estudamos nas aulas de Geografia, é muito legal." 


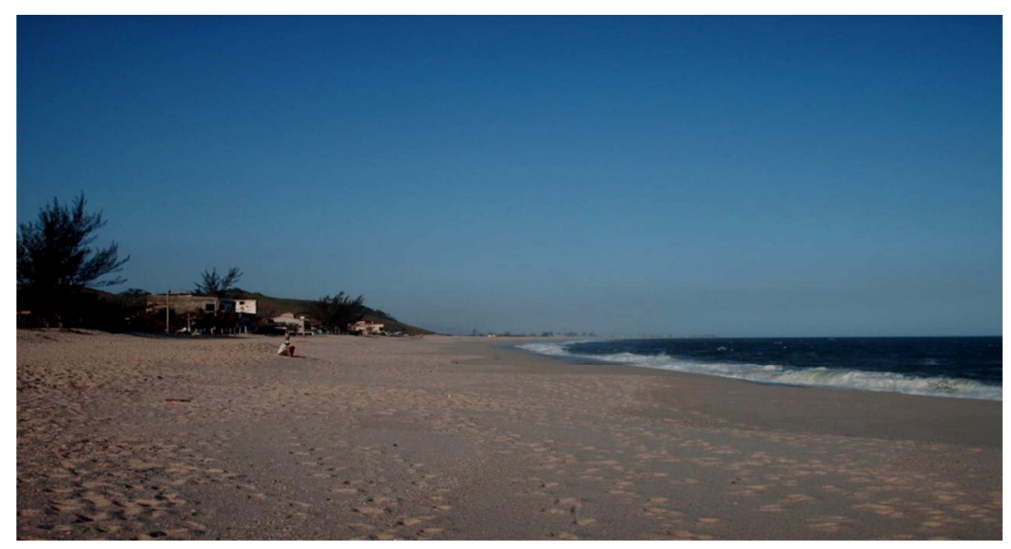

Figura 2 - Fotografia da Praia de Itaipuaçu - Maricá - RJ

\section{Ecossistema de Restinga}

O grupo de alunos responsável pelo Ecossistema de Restinga foi o mais entusiasmado ao retornar dos trabalhos de campo. Durante a organização da exposição eles convidaram membros de outros grupos da sala para participarem de audiências públicas na prefeitura e reuniões em defesa da restinga, já que havia uma discussão no município para a instalação de um resort na Área de Preservação Ambiental (Figura 3).

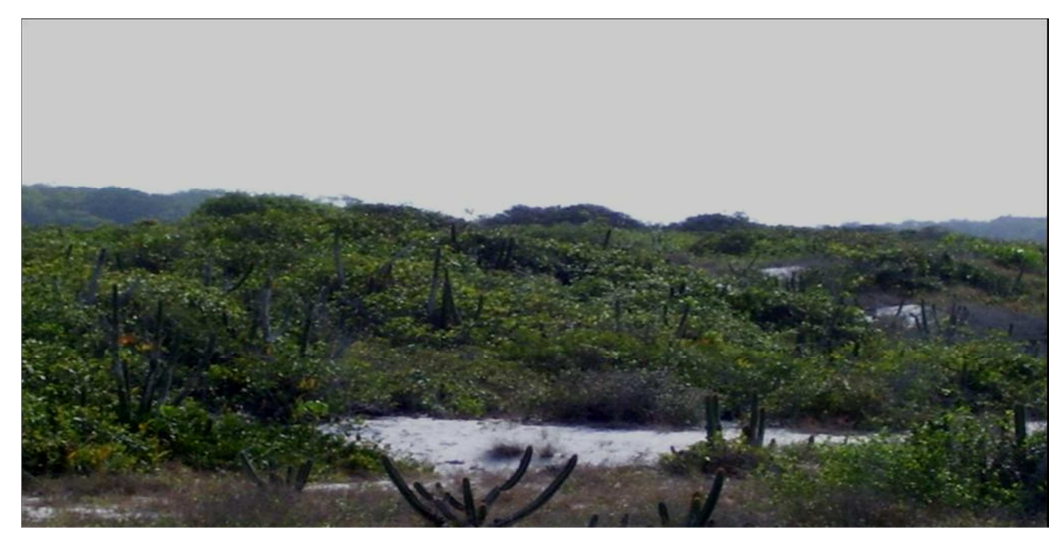

Figura 3 - Fotografia do ecossistema de restinga do município de Maricá - RJ -

Este grupo que a princípio achava a restinga "um monte de areia e cactos" passou a divulgar a diversidade encontrada neste ecossistema, sentindo-se felizardos por terem animais em seus quintais que não existem em nenhum outro lugar do mundo, como o lagarto de cauda verde Cnemidophorus littoralis (Rocha et al., 2000). No dia da exposição eles apresentaram uma maquete mostrando o cordão de restinga que acompanha o litoral e defenderam junto aos visitantes a importância deste ecossistema, mostrando sua formação e a sua ligação com o 
sistema lagunar. Além disso, distribuíram prospectos contra a instalação do empreendimento na região. Várias discussões surgiram neste grupo, mas todos muito entusiasmados com o que leram e viram:

"e pensar que esse lagarto verde foi descoberto aqui, perto de casa..."

"agora entendo o porquê da luta de classes que o professor de História tanto fala. Os pescadores artesanais vão ficar sem trabalho com a implantação do hotel de luxo!"

\section{Sistema Lagunar}

O grupo que visitou o sistema Lagunar realizou uma saída de campo onde fotografaram (Figura 4) e filmaram áreas preservadas bem como áreas degradadas. Estas imagens foram organizadas para a apresentação na exposição como um grande painel. O relato do grupo demonstrou desagrado com a observação de grande quantidade de dejetos lançados nas lagunas, em especial esgoto doméstico, uma vez que o entorno do sistema lagunar está repleto de loteamentos e condomínios. Este grupo interagiu bastante com o grupo de restinga, participando também das reuniões para a preservação da APA. Com o grupo de Mata Atlântica houve também associações de imagens para mostrar a importância da vegetação na manutenção do sistema hídrico da região.

"As pessoas se esquecem que se contaminarem o lençol freático ficaremos sem água potável."

"O problema da falta de saneamento básico nunca ficou tão claro para mim quanto agora, depois de visitar áreas conservadas e áreas degradadas."

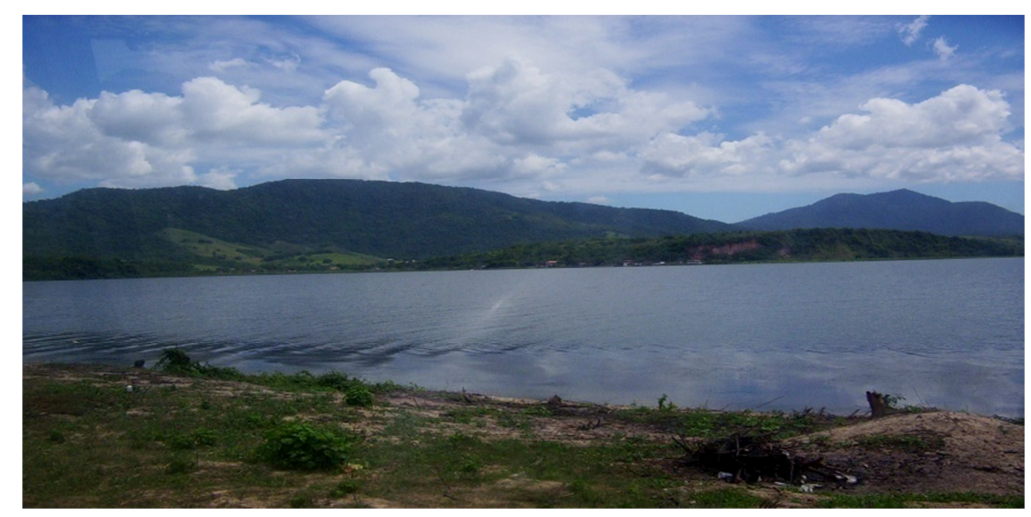

Figura 4 - Fotografia da Laguna de Ponta Negra- Maricá $-R J-$ 


\section{Discussão}

Segundo Gardner, poucos negariam à escola o papel primordial na tarefa de inculcar conhecimentos e verdades (Gardner et al., 1998). Os Parâmetros Curriculares Nacionais (PCN) propõem que, no processo educacional escolar, os jovens adquiram uma postura crítica sobre questões ambientais do seu dia-a-dia (Brasil, 2002). Muitas vezes as práticas educativas restringem-se ao domínio cognitivo, sem preverem métodos que contemplem a formação de valores nos alunos. Os conhecimentos adquiridos só terão reflexo na vida prática dos indivíduos se forem aplicados para a formação de valores (Seniciato e Cavassan, 2004). Para que eles adotem atitudes ambientalmente saudáveis não basta à conscientização da preservação ambiental, mas sim a construção de um saber específico, relacionado ao ambiente local. Esta construção poderá provocar mudanças significativas nas práticas de ensino-aprendizagem e no cotidiano das pessoas (Nicolier e Velasco, 2009).

Assim sendo o desenvolvimento do Projeto "Conhecer para conservar" superou quaisquer expectativas com relação à construção integral do indivíduo. A ação interdisciplinar ocorrida durante o projeto ratificou a discussão de Hartmann e Zimermann, onde a interdisciplinaridade deve ir além da integração de conhecimentos, mas sim a interação entre docentes para produzir atividades articuladas entre si, aproveitando as contribuições de diferentes disciplinas e profissionais. Estes autores afirmam que uma ação interdisciplinar é aquela realizada por dois ou mais professores que, por meio do diálogo, negociam atividades conjuntas para conectar saberes específicos das suas disciplinas para o estudo de um objeto de conhecimento comum. (Hartmann e Zimmermann, 2007) A ação desenvolvida neste trabalho envolveu 3 disciplinas cujos docentes tinham afinidades, muitas vezes discutindo na sala dos professores questões de interface de suas disciplinas, porém sem sistematizá-las. Logo, a "cumplicidade docente" permitiu que houvesse uma parceria entre as diversas áreas do conhecimento, de modo a enriquecer a todos através das atividades interdisciplinares. A ação conjunta facilitou ainda a avaliação dos alunos, onde o conjunto de produtos gerados foi usado como base de análise (produção textual, exposição oral, confecção de materiais, interação no grupo, materiais multimídia). O desenvolvimento da atividade descrita neste trabalho foi muito gratificante para os professores envolvidos, onde todos puderam perceber como a ação pedagógica surtiu efeito nos alunos, levando-os a se tornarem cidadãos mais críticos e questionadores.

A exemplo disso, Teixeira discute a interação entre a pedagogia histórico crítica e o ensino com enfoque CTS, demonstrando que uma ação pedagógica na qual os conteúdos específicos possam ser analisados de forma conjunta por diversas disciplinas e contextualizado na realidade do aluno, permite a formação mais integral e consciente do aluno. (Teixeira, 2003) 
Muito mais do que conhecer fauna e flora, aspectos geográficos e históricos, os alunos reconheceram no seu cotidiano temas antes restritos as salas de aula, tornando-se atores efetivos do processo de aprendizagem, como discutem Marandino e Selles e ainda Gadotti (Gadotti, 2004; Marandino et al., 2009). A visita a ecossistemas pode oferecer um contato mais direto com o objeto de estudo, proporcionando melhor entendimento dos procedimentos utilizados para a compreensão do ambiente natural (Marandino et al., 2009). Para estes alunos o projeto se tornou muito mais que uma ação pedagógica. A sensibilização gerada pela luta das questões ambientais levou a união da turma, antes dividida em pequenos grupos, fortalecendo os laços de amizade. A demonstração de tal fato ocorreu não só durante os trabalhos (Figura 5), mas também na cerimônia de formatura, onde o orador da turma citou o trabalho desenvolvido como sendo fundamental para a chegada de todos até ali. Os vídeos produzidos pelos alunos foram projetados e a música tema "Pescador de ilusões" do grupo Rappa, usada durante a entrega dos diplomas. A participação integral da turma surpreendeu o grupo de professores e fez com que colegas de outras áreas também participassem mesmo que em menor escala das atividades desenvolvidas. $\mathrm{A}$ comunidade se mostrou muito receptiva às informações levadas na cartilha produzida pelos alunos e diversos pais se prontificaram a auxiliar em outros eventos. $\mathrm{O}$ ambiente escolar foi contagiado pelo projeto da turma de terceiro ano, a ponto de a escola solicitar ao grupo de professores a continuidade nos anos seguintes do projeto citado. Evidentemente que por mais que os professores estejam disponíveis para esta realização, será necessário um encontro de idéias e ideais no grupo de estudantes dos próximos anos para que estes também sejam sensibilizados e estejam abertos à participação nas atividades.

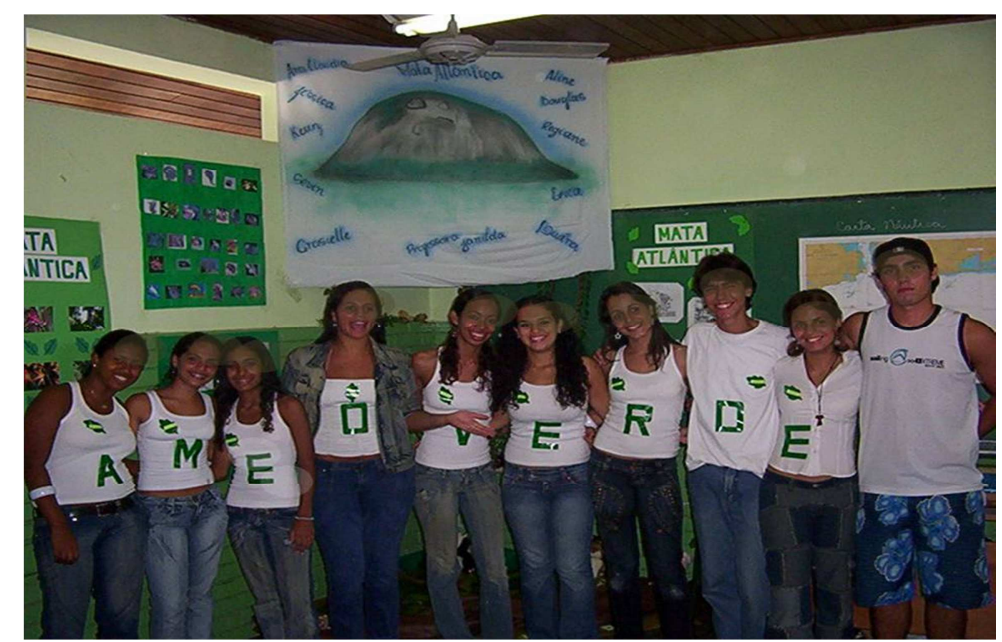

Figura 5 Fotografia de parte da exposição desenvolvida pelos alunos do Colégio Dr João

\section{Referências}

Auler, D., (2007). "Enfoque Ciência-Tecnologia-Sociedade : Pressupostos Para O Contexto Brasileiro." Ciência e Sociedade 1(no especial).

R. B. E. C. T., vol 4, núm 3, set./dez. $2011 \quad$ ISSN - 1982-873X 
Batista, I. d. L.eSalvi, R. F., (2006). "Perspectiva Pós-Moderna E Interdisciplinaridade Educativa: Pensamento Complexo E Reconciliação Integrativa." Ensaio 8(2): 147-159.

Brasil (1988). Constituição Da República Federativa Do Brasil. Civil, C. Brasília: 112-113.

Brasil (2002). Parâmetros Curriculares Nacionais Do Ensino Médio Tecnológica, S. d. E. M. e. Brasília.

Brum, C. (2004). Contando a História De Maricá. Maricá, Gráfica Boas Novas.

CN-RBMA. (2004). "Mapa Da Vegetação Brasileira." Retrieved 01-09-2011, from www.rbma.org.br.

Cruz, C. B. M., Carvalho, W. J., et al. (1996). Impactos Ambientais No Sistema Lagunar MaricáGuarapina. Anais VIII Simpósio Brasileiro de Sensoriamento Remoto

INPE. Salvador, Brasil: 137-138.

Gadotti, M. (2004). "Interdisciplinaridade : Atitude E Método. ." 20/05/2010, from www.paulofreire.org.br.

Gardner, H., Kornhaber, M. L., et al. (1998). Inteligência : Múltiplas Perspectivas. Porto Alegre, Artmed.

Goldman, L. (1979). Dialética E Cultura. Rio de Janeiro, Editora Paz e Terra.

Hartmann, A. M.eZimmermann, E., (2007). "O Trabalho Interdisciplinar No Ensino Médio: A Reaproximação Das "Duas Culturas"." Revista Brasileira de Pesquisa Ensino de Ciências 7(2).

IBGE, F. I. B. d. G. e. E.-. (1992). Manual Técnico Da Vegetação Brasileira. ambientais, D. d. R. n. e. e. Rio de Janeiro, IBGE. 1: 12-32.

Jacobi, P., (2003). "Educação Ambiental, Cidadania E Sustentabilidade." Cadernos de Pesquisa 118(março): 189-205.

Jardim, A., Aguiar, J. R., et al. (2004). Meio Ambiente Local: Você Conhece? Anais do VII Encontro de Educação Ambiental do estado do Rio de Janeiro, Rio de Janeiro.

Jones, A.eMoreland, J., (2004). "Enchancing Praticing Primary School Teacher's Pedagogical Content Knowledge in Technology." International Journal of Technology and Design Education 14: $121-140$.

Leff, E. (2000). Complexidade, Interdisciplinaridade E Saber Ambiental. Interdisciplinaridade Em Ciências Ambientais. Philippi jr, A., Tucci, C. E. M., Hogan, D. J. eNavegantes, R. São Paulo, Signus Editora: 327. 
Lewis, T., (2005). "Creativity: A Framework Fot the Design/Problem Solving Discourse in Technology Education." Journal of Technology Education 17(1): 35-52.

Marandino, M., Selles, S. E., et al. (2009). Ensino De Biologia: Histórias E Práticas Em Diferentes Espaços Educativos. São Paulo, Cortez.

Mishra, P.eKoehler, M., (2006). "Technological Pedagogical Content Knowledge : A Framework for Teacher Knowledge." Teachers College Records 108(6): 1017-1054.

Morin, E.eLe Moigne, J.-L. (2000). A Inteligência Da Complexidade. São Paulo, Fundação Peirópolis.

Nicolier, V.eVelasco, F. G. C., (2009). "Conhecer a Mata Atlântica Na Infância: Uma Contribuição Da Teoria Das Inteligências Múltiplas Para a Educação Ambiental." Investigações em Ensino de Ciências 14(3): 421-456.

Padua, S. M.eTabanez , M. F. (1997 ). Educação Ambiental Caminhos Trilhados No Brasil Brasília, Ed. Gráfica Fotolito.

Pereira, M. C. A., Araujo, D. S. D., et al., (2001). "Estrutura De Uma Comunidade Arbustiva Da Restinga Da Barra De Maricá-Rj." Revista Brasileira de Botânica 24(3): 273-281.

Pinheiro, N. A. M., Silveira, R. M. C. F., et al., (2007). "Ciência, Tecnologia E Sociedade: A Relevância Do Enfoque Cts Para O Contexto Do Ensino Médio." Ciência e Educação 13(1): 71-84. Rocha, C. F. D., Araújo, A. F. B., et al., (2000). "New Cnemidophorus (Squamata; Teiidae) from Coastal Rio De Janeiro State, Southeastern Brazil." Copeia May(2): 501-509.

Rodrigues, G. S. d. S. C.eColesanti, M. T. d. M., (2008). "Educação Ambiental E as Novas Tecnologias De Informação E Comunicação." Sociedade \& Natureza 20(1): 51-66.

Santos, W. L. P.eMortimer, E. F., (2002). "Uma Análise De Pressupostos Teóricos Da Abordagem CT-S( Ciência-Tecnologia-Sociedade) No Contexto Da Educação Brasileira." Ensaio 2(2): 1-23.

Seniciato, T.eCavassan, O., (2004). "Aulas De Campo Em Ambientes Naturais E Aprendizagem Em Ciências - Um Estudo Com Alunos Do Ensino Fundamental." Ciência \& Educação 10(1): 133-147.

Teixeira, P. M. M., (2003). "A Educação Científica Sob a Perspectiva Da Pedagogia Histórico-Crítica E Do Movimento C.T.S. No Ensino De Ciências." Ciência \& Educação 9(2): 177-190.

Thiesen, J. d. S., (2008). "A Interdisciplinaridade Como Movimento Articulador No Processo De Ensino-Aprendizagem." Revista Brasileira de Educação 13(39): 545-553. 
Janilda Pacheco da Costa. Secretaria de Estado de Educação do Estado do Rio de Janeiro. Professora de Biologia da Secretaria de Estado de Educação do Estado do Rio de Janeiro. Mestre em Ciências Médicas pela Universidade Federal Fluminense. Doutoranda em Biologia das Interações na Universidade Federal Fluminense. janildacosta@yahoo.com.br Antonio Carlos Concellos Costa. Professor de História da Secretaria Estadual de Educação do Estado do Rio de Janeiro. jpcosta8@ibest.com.br

Sonia Peres. Professora de Geografia da Secretaria de Estado de Educação do Estado do Rio de Janeiro. Especialista em Planejamento Ambiental pela Universidade Federal Fluminense. speres16@yahoo.com.br Gerlinde Agate P. Brasil Teixeira. Universidade Federal Fluminense. Instituto de Biologia Departamento de Imunobiologia. Doutora em Patologia. gerlinde@vm.uff.br 